JGG 2021;69:255-257

doi: $10.36150 / 2499-6564-N 453$

\title{
Are hearing and olfaction disorders more common in older patients with diabetes? Are hearing loss and olfactive disfunction a risk factor for progression of functional decline and disability?
}

\author{
Niccolò Favaretto \\ Department of Neuroscience, Otolaryngology Section, University of Padua, Padua, Italy
}

\section{RECOMMENDATIONS}

A. All geriatric DM patients should undergo audiological and audiometric examinations, followed by annual/twice-yearly check-ups.

B. More attention should be given to auditory rehabilitation programs, with prescription of appropriate hearing aids, to improve quality of life and cognitive functioning.

C. If concerns arise about a patient's hearing status, they should undergo pure tone audiometry, but also speech audiometry (including a measurement of speech recognition thresholds, preferably in both quiet and noise), which tries to reproduce daily life condition and to assess actual speech comprehension in a daily life-like condition.

Received: July 30, 2021
Accepted: September 16, 2021

\section{Correspondence Niccolò Favaretto Department of Neuroscience, Otolaryngology Section, University of Padua, VIII Febbraio 2, 35122 Padua, Italy \\ E-mail: niccolo.favaretto@unipd.it}

How to cite this article: Favaretto $\mathrm{N}$. Are hearing and olfaction disorders more common in older patients with diabetes? Are hearing loss and olfactive disfunction a risk factor for progression of functional decline and disability? Journal of Gerontology andGeriatrics2021;69:255-257.https://doi. org/10.36150/2499-6564-N453

(C) Copyright by Società Italiana

di Gerontologia e Geriatria (SIGG)

\section{(c) (i) () $\Theta$}

OPEN ACCESS

This is an open access article distributed in accordance with the CC-BY-NC-ND (Creative Commons Attribution-NonCommercial-NoDerivatives 4.0 International) license. The article can be used by giving appropriate credit and mentioning the license, but only for non-commercial purposes and only in the original version. For further information: https://creativecommons.org/licenses/by-nc-nd/4.0/deed.en
D. All geriatric DM patients should undergo screening to evaluate olfaction and taste functioning, with regular follow-ups to assess any potential impact on nutritional status.

\section{STRENGTH OF THE RECOMMENDATIONS}

The quality of the evidence is moderate. Recommendations are supported by published evidence and best practice (supported by expert opinion).

\section{SUPPORTING EVIDENCE}

See appendix.

\section{AREAS OF UNCERTAINTY AND FUTURE PERSPECTIVES}

Many studies on hearing performance have been conducted on middleaged T2DM patients, but there is less clarity in geriatric patients, possibly because they start to develop also age-related hearing loss. Further studies are needed to clarify whether decline in olfaction and taste is a result of ongoing neurodegenerative disease or whether it directly contributes to causing or accelerating cognitive decline. 


\section{APPENDIX}

Hearing loss is considered to be the second most frequent disorder in older people, and it is present in a third of people aged 65 or more, and almost $50 \%$ of those over 75 years ${ }^{1}$. There is growing evidence that hearing loss is associated in some way to cognitive decline. The proposed mechanisms behind this association include direct neurodegenerative damage to auditory and central nervous systems, indirect associations through social isolation, depression, and reduced sensory stimulation, and accelerated brain atrophy cause by the recruitment of additional cognitive resources to understand language and other auditory stimuli ${ }^{2}$.

The association between DM and hearing loss is complex: most available studies show an association between auditory deficits and $\mathrm{DM}^{3}$. This association is widely accepted for middle-aged patients with DM, with a marked increase for high-frequency sounds. Some authors have also reported a higher risk of developing incident hearing loss in DM patients ${ }^{3,4}$ and there is evidence that this is associated with $\mathrm{HbA} 1 \mathrm{c}$ values ${ }^{4}$, suggesting a potential pathogenic role of glycemic control.

There is less clarity about this association in older people ${ }^{5}$, possibly because they start to develop age-related hearing loss. Therefore, quantitative assessments of auditory thresholds are necessary to accurately assess the potential effect of T2DM on hearing loss in the elderly. Geriatric DM patients seem to have faster age-related hearing loss than non-diabetic patients ${ }^{6}$ and, in general, longer DM disease duration is associated with auditory deterioration ${ }^{7}$. This is particularly important among older people with a long history of $\mathrm{DM}$; in these patients age-related hearing loss and DM may act in synergy to accelerate and exacerbate hearing loss.

Histopathological studies on animal models and patients have revealed microangiopathic changes in the capillaries of the stria vascularis in the cochlea (particularly in the basal curve, which is responsible for high frequency hearing) ${ }^{8}$ and damage to external hearing cells ${ }^{9}$; features which are also present in age-related hearing loss ${ }^{10,11}$. Some authors also report that hearing loss is accelerated in people with poorer initial hearing thresholds ${ }^{12}$, while other authors report the opposite ${ }^{13}$, although they show only a small decrease in the progression of hearing loss in patients with poorer initial thresholds.

Several studies have highlighted an association between olfactory hypofunction and DM ${ }^{14}$, possibly in relation to antidiabetic treatment ${ }^{15}$ and insulin-resistance ${ }^{16}$, but there is little data available for geriatric DM patients. Conversely, there is less clarity about taste: some authors also report that this sensory function is compromised ${ }^{17}$, while others have not found any significant association ${ }^{18}$. Both taste and olfaction contribute to the perception of complex flavors and, interestingly, olfaction and taste functioning appears to be related to eating behaviour in patients with DM; impairment in olfaction and taste can lead to a dysregulation of food intake in DM patients ${ }^{18,19}$, leading to weight increase and obesity, which can complicate the disease and the patient's general clinical situation.

There is no specific data on taste and olfaction in geriatric DM patients, but these senses are often compromised in older people during the early stages of neurodegenerative diseases like Alzheimer's or parkinsonism ${ }^{20}$. Further studies are needed to clarify whether decline in olfaction and taste is a result of ongoing neurodegenerative diseases or whether it directly contributes to causing or accelerating cognitive decline.

Ethical consideration

Studies included raised no significant ethical issues.

\section{Acknowledgement}

None.

Funding

None.

Conflict of interest

The Author declares no conflict of interest.

\section{References}

\section{HEARING Loss}

1 World Health Organization (http://www.who.int/en/ news-room/fact-sheets/detail/ageing-and-health).

2 Stahl SM. Does treating hearing loss prevent or slow the progress of dementia? Hearing is not all in the ears, but who's listening? CNS Spectr 2017;22:247-250. https:// doi.org/10.1017/s1092852917000268

3 Akinpelu OV, Mujica-Mota M, Daniel SJ. Is type 2 diabetes mellitus associated with alterations in hearing? A systematic review and meta-analysis. Laryngoscope 2014;124:767-776. https://doi.org/10.1002/ lary. 24354

4 Kim MB, Zhang Y, Chang Y, et al. Diabetes mellitus and the incidence of hearing loss: a cohort study. Int J Epidemiol 2017;46:717-726. https://doi.org/10.1093/ije/dyw243

5 Uchida Y, Sugiura S, Ando F, et al. Diabetes reduces auditory sensitivity in middle-aged listeners more than in elderly listeners: a population- based study of age-related hearing loss. Med Sci Monit 2010;16:PH63-8.

6 Mitchell P, Gopinath B, McMahon CM, et al. Relationship of type 2 diabetes to the prevalence, incidence and progression of age-related hearing loss. Diabet Med 2009;26:483488. https://doi.org/10.1111/j.1464-5491.2009.02710.x 
7 Gupta S, Eavey RD, Wang M, et al. Type 2 diabetes and the risk of incident hearing loss. Diabetologia 2019;62:281285. https://doi.org/10.1007/s00125-018-4766-0

8 Akinpelu OV, Ibrahim F, Waissbluth S, et al. Histopathologic changes in the cochlea associated with diabetes mellitus-a review. Otol Neurotol 2014;35:764-774. https://doi. org/10.1097/mao.0000000000000293

9 Fukushima H, Cureoglu S, Schachern PA, et al. Effects of type 2 diabetes mellitus on cochlear structure in humans. Arch Otolaryngol Head Neck Surg 2006;132:934-938. https://doi.org/10.1001/archotol.132.9.934

10 Kurata N, Schachern PA, Paparella MM, et al. Histopathologic evaluation of vascular findings in the cochlea in patients with presbycusis. JAMA Otolaryngol Head Neck Surg 2016;142:173-178. https://doi.org/10.1001/ jamaoto.2015.3163

11 Ueberfuhr MA, Fehlberg H, Goodman SS, et al. A DPOAE assessment of outer hair cell integrity in ears with agerelated hearing loss. Hear Res 2016;332:137-150. https:// doi.org/10.1016/j.heares.2015.11.006

12 Linssen AM, van Boxtel MP, Joore MA, et al. Predictors of hearing acuity: cross-sectional and longitudinal analysis. J Gerontol A Biol Sci Med Sci 2014;69:759-765. https://doi. org/10.1093/gerona/glt172

13 Rigters SC, van der Schroeff MP, Papageorgiou G, et al. Progression of hearing loss in the aging population: repeated auditory measurements in the Rotterdam Study. Audiol Neurootol 2018;23:290-297. https://doi. org/10.1159/000492203

\section{SMELL AND TASTE}

14 Le Floch JP, Le Lièvre G, Labroue M, et al. Smell dysfunction and related factors in diabetic patients. Diabetes Care 1993;16:934-937. https://doi.org/10.2337/diacare.16.6.934

15 Chan JYK, García-Esquinas E, $\mathrm{Ko} \mathrm{OH}$, et al. The association between diabetes and olfactory function in adults. Chem Senses 2017;43:59-64. https://doi.org/10.1093/ chemse/bjx070

16 Min JY, Min KB. Insulin resistance and the increased risk for smell dysfunction in US adults. Laryngoscope 2018;128:1992-1996. https://doi.org/10.1002/lary.27093

17 De Carli L, Gambino R, Lubrano C, et al. Impaired taste sensation in type 2 diabetic patients without chronic complications: a case-control study. J Endocrinol Invest 2018;41:765772. https://doi.org/10.1007/s40618-017-0798-4

18 Rasmussen VF, Vestergaard ET, Hejlesen O, et al. Prevalence of taste and smell impairment in adults with diabetes: a cross-sectional analysis of data from the National Health and Nutrition Examination Survey (NHANES). Prim Care Diabetes 2018;12:453-459. https://doi.org/10.1016/j. pcd.2018.05.006

19 Zhang Z, Zhang B, Wang X, et al. Olfactory dysfunction mediates adiposity in cognitive impairment of type 2 diabetes: insights from clinical and functional neuroimaging studies. Diabetes Care 2019;42:1274-1283. https://doi. org/10.2337/dc18-2584

20 Doty RL. Age-related deficits in taste and smell. Otolaryngol Clin North Am 2018;51:815-825. https://doi. org/10.1016/j.otc.2018.03.014

\author{
This statement is: \\ $\otimes$ Recommendation (supported by published evidence) \\ $\bowtie$ Best practice (supported by expert opinion)
}

Quality of the evidence (in the case of recommendation):
$\square$ Low
$\otimes$ Moderate
$\square$ High

